\title{
Bacterial isolates of Tonsillitis and Pharyngitis in a Paediatric casualty setting
}

\author{
${ }^{1}$ Wilson E. Sadoh, ${ }^{2}$ Ayebo E. Sadoh , ${ }^{3}$ Adegbenro O. Oladipo, \\ ${ }^{4}$ Olusola O. Okunola
}

\begin{abstract}
SUMMARY
A prospective study was carried out to determine the pattern of bacterial isolates and their antibiotic sensitivity amongst children with tonsillopharyngitis. Consecutive children presenting with sorethroat, difficulty with swallowing, fever and/ or evidence of inflamed pharynx and/ or tonsils at the paediatric casualty of the University of Benin Teaching Hospital, Benin City, between February and October 2006 were recruited for the study. The patient's biodata were obtained and socioeconomic status was determined. Throat swabs were taken for microbiologic analysis. Seventy three throat swabs were analysed. Bacteria were isolated from 39 patients. Of which 19 (48.72\%) were $B$ haemolytic Streptococcus (BHS). others were S. aureus five (12.83\%), seven (17.95\%) were Klebsiella mirabilis and three $(7.69 \%)$ each of Pseudomonas aeroginosa and Proteus mirabilis. BHS and S. aureus showed $100 \%$ sensitivity to cefuroxine, azithromycin, ceftazidine and genticin. All the isolates had little or no sensitivity to ampicillin and cotrimoxazole. BHS is a significant cause of pharyngitis and tonsillitis in our environment and therefore poses a potential danger of rheumatic fever and rheumatic heart disease, a non-suppurative sequalae of BHS. Ampicillin and cotrimoxazole two affordable and commonly available drugs are ineffective in tonsillitis and pharygitis.
\end{abstract}

\section{INTRODUCTION}

Pharyngitis and tonsillitis are two common upper respiratory tract infections(URTI) causing ill health in children presenting to primary care physicians.1,2 Although most cases of pharyngitis/ tonsillitis are viral in

KEYWORDS: Tonsillitis, pharyngitis, streptococcus

${ }^{1}$ Department of Child Health, Lecturer/ Consultant Paediatrician, ${ }^{2}$ Institute of Child Health, Research Fellow/ Consultant Paediatrican, ${ }^{3}$ Department of Paediatrics Faith Medical Hospital, University of Benin/ University of Benin Teaching Hospital, Benin City.

Correspondence author: W.E. Sadoh sadohehi@yahoo.com

(C) CMS UNIBEN JMBR 2007 EDITION; VOL (1\& 2); 5-11 origin, ${ }^{3}$ bacterial causes are important because of the non suppurative sequalae like rheumatic fever and rheumatic heart disease in group $A \beta$ hemolytic Streptococcus (GABHS) infection. Rheumatic fever (RF) and its cardiac complication of rheumatic heart disease (RHD) remain major health problems in developing countries. ${ }^{4,5}$

There have been reported outbreak of streptococcal infections amongst schoolchildren in the United states. ${ }^{6}$ The introduction of an invasive strain into a

Key words: 
closed population and increase in the throat carriage rate of the invasive streptococcus among community school aged children were strongly associated with the outbreaks. ${ }^{6}$ Such outbreak contributed to increased morbidity including rheumatic fever and RHD.

In Jos, Nigeria, streptococcus pneumoniae accounted for over one third of bacterial isolates causing URTI in under five children. ${ }^{7}$ The streptococcal throat carriage rate was 9.78\% amongst primary school pupils in Benin, Nigeria. ${ }^{8}$ This suggests significant probability of rheumatic fever and rheumatic heart disease among children in this community.

Early treatment of GABHS URTI has been shown to prevent rheumatic fever. ${ }^{9}$ It is therefore important to evaluate the pattern of bacterial URTI, determine the frequency of GABHS involvement and their current susceptibility to various antibiotics therapy. This will facilitate formulation of empirical antibiotic therapy especially in clinical setting with poor microbiological facilities. A prospective study was therefore carried out to determine the pattern of bacterial isolates causing tonsillitis/ pharyngitis and their antibiotic sensitivity at the paediatric casualty of the University of Benin Teaching Hospital, Benin City, Nigeria.

\section{PATIENTS AND METHODS}

Consecutive children presenting with pharyngitis or tonsillitis or both at the paediatric casualty of the University of Benin Teaching Hospital, Benin City, between February and October 2006 were recruited for the study. Inclusion criteria: patients with a history of sorethroat, difficulty swallowing, fever (Including a recorded temperature of $>$ $38.0^{\circ}$ at presentation) and/ or evidence of inflamed tonsils/ pharynx (presence of erythema and exudates on the pharynx and/ or tonsils on examination of the throat and anterior cervical adenitis). Cervical adenitis was adjudged present if the anterior cervical lymph nodes were tender and palpable. All patients were seen by the attending paediatrician (Who was a senior registrar or a registrar. They were trained by one of the authors on how to make the diagnosis and obtain throat swab). Patients who were receiving or had received antibiotics within two weeks of presentation were excluded.

The patients' biodata of age and sex were obtained and socioeconomic status (SES) was determined by the method described by Olusanya et al. ${ }^{10}$ The clinical features in each case were documented. Patients who had hyperaemia, exudates or ulcers on the pharyngeal wall (excluding the tonsils) were said to have pharyngitis, while if these findings were restricted to the tonsils, a diagnosis of tonsillitis was made. When the features were found in both areas, the term tonsillopharyngitis was used.

Throat swabs were taken by the attending paediatrician from each patient using a sterile swab stick. The swab stick was introduced into a well exposed mouth with the tongue depressed by a wooden spatula where necessary and visible exudates or hyperaemic areas on the pharyngeal or tonsillar walls were swabbed. The swab stick was carefully replace in its sheath and sent for microbiological analysis within 1 hour or kept in Stuart medium before being analysed at the research laboratory of the Child Health department of the same hospital. The microbiological analysis was done by a medical laboratory scientist. Swabs were simultaneously plated on a blood agar, Mac Conkey and Chocolate agar media and incubated at $37^{\circ} \mathrm{C}$ for 48 hours. Growths were further sub-cultured to identify species. Cultures were considered negative if there was no significant bacterial growth after 48 
hours. Growths of Streptococcus pyogenes, Staphylococcus aureus, Klebsiella aerogenes, Peudomonas aerogenosa, and Eshericheae coli on any of the media were identified by standard methods. $ß$ hemolytic streptococcal (BHS) colonies could not be classified further into their Lancefield groups because of non availability of this facility. The sensitivity of the isolates was tested against ten common antibiotics, using Biotec gram positive and negative discs (Batch number C124679).

\section{STATISTICAL ANALYSIS}

Data were analysed using SPSS 11.0 version. Simple proportions were represented in percentages. The sensitivity (The number of patients with bacteria isolates as a percentage of patients with the symptom) and specificity (The number of patient without bacterial isolate as a \% of patients without the symptom) of each of the clinical symptom/ sign in predicting possible bacteria upper respiratory tract infections were determined. Chi-square was used to test associations and Student's t test to test the difference between means. $\mathrm{p}<0.05$ was considered statistically significant.

\section{RESULTS}

There were 73 patients who met the study criteria and their samples were analysed. Of which 41(56.16\%) were males and $32(43.84 \%)$ were females, giving a M: F ratio of $1.3: 1$. The mean age was $3.68 \pm 3.68$ years (range, 3 month 16 years), 19(26.03\%) were infants and 60(82.19\%) were aged between 1 and 5 years. Thirty seven 37(50.68\%) patients were from high socioeconomic class, $14(19.18 \%)$ from middle class and 22(30.14) from low class.

Most of the patients 54 (73.97\%) had t onsillitis , $11(15.07 \%)$ h ad tonsillopharyngitis while eight (10.96\%) had pharygitis. Fever and inflamed tonsils/pharynx were the most frequent signs or symptoms occurring in 65 (89.04\%) and 64 $(87.67 \%)$ of subjects respectively while cervical adenitis $20(27.39 \%)$ and presence of exudates 19 (26.03\%) were the least frequent signs (Table I).

Although all the clinical features showed relatively low sensitivity and specificity, inflamed tonsils (64.81) and cough (64.28\%) were the most sensitive while fever (55.38\%) and cervical adenitis (55.00\%) were the least sensitive. Cough (54.84\%) and presence of exudates (50.00\%) showed the most specificity while fever (37.50\%) and inflamed tonsils $(15.80 \%)$ had the least specificity. The highest positive predictors of bacterial URTI were fever $(87.80 \%)$ and inflamed tonsils $(85.37 \%)$ and the least predictors were history of sorethroat $(30.00 \%)$ and difficulty with swallowing (30.00\%) (Table 1).

The most frequently associated disease was malaria 17 (23.29\%) and otitis media 4 (5.48\%). Bronchial asthma and paediatric AIDS were present in 3 (4.11\%) patients each. Others were measles, mumps, rheumatic heart disease and sickle cell anaemia which had occurred in 1 (1.37\%) patient each.

Bacteria were isolated from 39 (53.42\%) subjects. Nineteen $(48.72 \%)$ of the isolates were BHS, while five (12.83\%) were Staphyloccocus aureus. Klebsiella spp, Proteus spp and Pseudomonas spp were recovered from the throat of seven (17.95\%), three $(7.69 \%)$ and three (7.69\%) subjects respectively (Table II). Of the 39 subjects with isolates, 17(43.59\%) were males and 22 females giving $\mathrm{M}: \mathrm{F}$ ratio of 1:1.3. The gender difference was not significant when compared to the study population $x^{2}=1.1146$, $\mathrm{p}=0.2845$. The mean age of those with isolates was $3.38 \pm 4.02$ years and this was not significantly different from the mean age of the study population, $\mathrm{t}=0.3979, \mathrm{p}=$ 0.6914 (CI 1.194 to 1.794 ). There were more 
patients 18(46.15\%) from high SES than middle seven (17.95\%) and low 14 (36.90\%). The patients who had isolates in each socioeconomic class did not significantly differ from those without isolates $x^{2}=$ $0.9844, \mathrm{p}=0.6133$. The 14 patients with Klebsiella mirabilis, Pseudomonas aeroginosa, Proteus mirabilis and Eshericheae coli had a mean age of $1.32 \pm$
0.94 years (range, 3months 4 years). They were significantly younger than the study population, $\mathrm{t}=2.374 ; \mathrm{p}=0.019$ and they were from the middle or low SES (Table II). BHS and S. aureus showed $100 \%$ sensitivity to cefuroxine, azithromycin, ceftazidime and Genticin but showed little or no sensitivity to ampicillin and cotrimoxazole, Table III.

\section{Table I}

The sensitivity, specificity and positive predictive values of clinical features in predicting bacteria URTI

\begin{tabular}{lccccccc}
\hline $\begin{array}{l}\text { Symptom/ } \\
\text { Signs }\end{array}$ & $\begin{array}{c}\text { Nowith } \\
\text { symptoms (\%) }\end{array}$ & $\begin{array}{c}\text { No without } \\
\text { symptoms }\end{array}$ & $\begin{array}{l}\text { Nowith } \\
\text { isolates }\end{array}$ & $\begin{array}{l}\text { Nowithout } \\
\text { Isolates }\end{array}$ & $\begin{array}{c}\text { Sensitivity } \\
\%\end{array}$ & $\begin{array}{c}\text { Specificity } \\
\%\end{array}$ & $\begin{array}{c}\text { Positive predictive } \\
\text { value }(\%)\end{array}$ \\
\hline Fever & $65(89.04)$ & 8 & 36 & 3 & 55.38 & 37.50 & 87.80 \\
Cough & $42(57.53)$ & 31 & 27 & 17 & 64.28 & 54.84 & 65.85 \\
Sorethroat & $20(27.39)$ & 53 & 12 & 25 & 60.00 & 47.17 & 30.00 \\
Difficult swallowing & $20(27.39)$ & 53 & 12 & 25 & 60.00 & 47.17 & 30.00 \\
Inflamed tonsils & $54(73.97)$ & 19 & 35 & 3 & 64.81 & 15.80 & 85.37 \\
Exudates & $19(26.03)$ & 54 & 12 & 27 & 63.16 & 50.00 & 30.77 \\
Cervical adenitis & $20(27.39)$ & 54 & 11 & 26 & 55.00 & 48.15 & 28.20 \\
\hline
\end{tabular}

\section{Table II}

Bacteria isolates and socioeconomic class

\begin{tabular}{lllll}
\hline Isolates & High & Mid & Low & Total No(\%) \\
\hline Bhaemolytic Streptococcus & 14 & 1 & 4 & $19(48.72)$ \\
Klebsiella mirabilis & 1 & 3 & 3 & $7(17.95)$ \\
Staphylococcus aureus & 3 & 1 & 1 & $5(12.83)$ \\
Pseudomonas aeroginosa_ & 0 & 0 & 3 & $3(7.69)$ \\
Proteus mirabilis & 0 & 1 & 2 & $3(7.69)$ \\
Eshericheae coli & 0 & 0 & 1 & $1(2.56)$ \\
Streptococcus viridans & 0 & 1 & 0 & $1(2.56)$ \\
\hline
\end{tabular}


41 Journal of Medicine and Biomedical Research

\section{Table III}

Antibiotic sensitivity of bacterial isolates

\begin{tabular}{llllll}
\hline Antibiotic & \multicolumn{2}{c}{ \% of bacteria isolates sensitive to antibiotics } & & \\
& $\begin{array}{l}\text { Streptococcus } \\
\text { Pyogenes }\end{array}$ & $\begin{array}{l}\text { Staphylococcus } \\
\text { aureus }\end{array}$ & $\begin{array}{l}\text { Klebsiella } \\
\text { mirabilis }\end{array}$ & $\begin{array}{l}\text { Pseudomonas } \\
\text { aeroginosa }\end{array}$ & $\begin{array}{l}\text { Proteus } \\
\text { mirabilis }\end{array}$ \\
\hline Cefuroxine & 100 & 100 & 100 & 66.7 & 100 \\
Genticin & 100 & 100 & 83.3 & 100 & 100 \\
Azithromycin & 100 & 100 & 100 & 100 & 100 \\
Ceftazidine & 100 & 100 & 83.3 & 100 & 66.7 \\
Amoxycillin & 88.2 & 100 & 50 & 0.0 & 100 \\
Streptomycin & 80.0 & 100 & 33.3 & 33.3 & 100 \\
Ampicillin & 0 & 0 & 0 & 0 & 0 \\
Cephalexin & 64.7 & 75 & 50 & 33.3 & 100 \\
Floxapen & 58.8 & 75 & 100 & 33.3 & 66.7 \\
Cotrimoxazole & 11.1 & 25 & 0.0 & 0.0 & 66.7 \\
\hline
\end{tabular}




\section{DISCUSSION}

Most of the patients in this study were under five years of age. This is in keeping with previous reports.7,11 The fact that these young children are still in the process of developing immunity to pathogens in their environment may explain this finding. That majority of the subjects were from high SES may reflect the likelihood that people from upper social class are more likely to seek medical attention for an upper respiratory tract infection.

Although sorethroat and difficulty in swallowing are major symptoms in tonsillitis/ pharyngitis, ${ }^{12,13}$ less than a third of the patients in this study presented with these complaints. This is because children seldom complain of sorethroat or difficulty in swallowing. ${ }^{14}$ Since almost a third of the studied patients were infants, complaint of sorethroat or difficulty with swallowing would obviously be less.

The use of individual clinical features as predictors of possible bacteria URTIs were poor as shown by their low sensitivity and specificity. This is consistent with other studies that showed the unreliability of using individual sign to predict possible bacteria tonsillitis/ pharyngitis. ${ }^{13,14}$

Almost half of the bacteria isolates were BHS, the predominance of this organism in this study is consistent with reports of other studies ${ }^{12,15}$. Although the Lancefield grouping could not be done to determine the proportion of the BHS that was group A (The group that is associated with RF and RHD), the high numbers of BHS underscores the continued potential danger posed by possible non-suppurative sequelae of RF and RHD in our community. The unusual presence of gram negative coliform organisms (Klebsiella, Proteus and Pseudomonas) in this study is noted. Since they are not traditional upper respiratory pathogens, it is possible that they could have been transferred from the anal region to the throat following poor personal hygiene. The fact that the patients with coliform organisms were significantly younger and were from low and middle SES lends credence to such possibility.

Our study showed that BHS and S. aureus had $100 \%$ sensitivity to cefuroxine, azithromycin and ceftazidime, three relatively expensive drugs, a finding corroborated by previous studies.16-18 It is worthy of note that amoxicillin showed more activity against the pathogens isolated compared to ampicillin in this study, despite the fact that both drugs are aminopenincillins and are suppose to have similar antibacterial activities. $^{19}$ Although the reason for this difference is not clear, we suspect it may not be unrelated to possible abuse of the cheaper ampicillin with resultant resistance. All pathogens showed little or no sensitivity to ampicillin and co-trimoxazole, two affordable drugs, whose normal antibacterial spectrum includes streptococcus pneumonia. ${ }^{19}$ This finding may also be due to abuse of these relatively cheap drugs.

A ten day course of penincillin $\mathrm{V}$ in 3 or 4 divided doses is the standard recommendation for treatment of streptococcal pharyngitis. ${ }^{20}$ The need to change this first line drug is being advocated by some workers due to increasing resistance of streptococcus to penicillin, because of difficulty with complying with the standard regimen and the non availability of paediatric preparations..$^{21-23}$ The magnitude of streptococcal resistance to penincillin $\mathrm{V}$ could not be evaluated in this study since sensitivity to it could not be tested due to nonavailability of the disc. We recommend cefuroxine and azithromycin as alternative drugs where the oral route is desired and ceftazidime as a choice drug for intravenous 
or intramuscular routes for streptococcal and staphylococcal infections. Where financial constraint is a major issue, amoxicillin an affordable drug with comparable sensitivity with the standard penicillin regimen, ${ }^{24}$ can be given both orally or intravenously. The coliform organisms showed good sensitivity to genticin, an affordable drug. Genticin would be particularly useful where the parenteral route of drug administration is indicated. However its suitability as a first line drug in infections by these pathogens is limited by the fact that it can only be administered parenterally.

\section{LIMITATION OF STUDY}

Since penicillin $\mathrm{V}$ is still the standard recommendation for treating streptococcal URTI, our inability to test bacterial isolates for sensitivity to it is noted as a limitation to this study. We therefore suggest future study to determine the sensitivity of upper respiratory pathogens to penicillin $\mathrm{V}$ in the study locale.

\section{ACKNOWLEDGEMENT}

We thank most sincerely the paediatric residents of the department of Child Health, University of Benin Teaching Hospital, who assisted us in obtaining relevant information and throat swabs from the subjects.

\section{References}

1. Teng CL, Shajahan Y, Khoo EM, Nurjahan I, Leong KC, Yap TG. The management of upper respiratory tract infection. Med J Malaysia 2001; 56: 260-266

2. West JV. Acute upper airway infections. Br Med Bull 2002; 61: 215230

3. Wald ER, Guerra N, Byers C. Upper respiratory tract infections in young children: duration of and frequency of complications. Pediatrics 1991; 87: 129-133
4. Markowitz M. Streptococcal disease in developing countries. Pediatr Infect Dis J 1991; 10: S11-S14

5. Eisenberg MJ. Rheumatic heart disease in the developing world: prevalence, prevention and control. Eur Heart J 1993; 4: 122-128

6. Cockerill FR 3rd, MacDonald KL, Thompson RL, Roberson F, Kohner PC, Besser-Wiek J et al. An outbreak of invasive streptococcal disease associated with high carriage rates of invasive clone among school aged children. JAMA 1997; 277: 38-43

7. Mawak JD, Ewelike IC, Lar PM, Zumbes HJ. Bacterial aetiologic agents associated with upper respiratory tract infections in children (under five years) attending selected clinics in Jos, Nigeria. Highland Med Research J 2006: 4: 22-30

8. Sadoh WE. Streptococcal throat carriage rate amongst primary school pupils in Egor Local Government Area of Edo State of Nigeria. A dissertation submitted to the West African College of Physicians, in part fulfillment of the fellowship of the college. 2001.

9. Memorandum from a joint WHO/ISFC meeting. Strategy for controlling rheumatic fever/ rheumatic heart disease, with emphasis on primary prevention. Bull Wld Hlth Org 1995; 73: $583-587$

10. Olusanya O, Okpere E, Ezimokhai M. The importance of socioeconomic class in voluntary fertility control in a developing country W Afri J Med 1985; 4: 205-212. 
11. Ahmed J, Zamal MM, Keramet Ali SM. Identification of serogroups of beta hemolytic streptococci in children with tonsillo-pharyngitis. Bangladesh Med Counc Bull 2003; 29: 113-7

12. Bisno AL. Acute pharyngitis. N Engl J Med 2001;344:205-211

13. Gunnarsson RK, Holm SE, Soderstrom M. The prevalence of potential pathogenic bacteria in nasopharyngeal samples from individuals with a respiratory tract infection and a sorethroat- implication for the diagnosis of pharyngotonsillitis. Fam Pract 2001; 18:266-271

14. Donner-Banzhoff N, Beck C, Meyer F, Werner JA, Baum E. Clinical findings in patients with sore throat A study on intra-observer reliability. Fam Pract 2002; 19: 466-468

15. Linder MD, Bates DW, Lee GM, Finkelstein JA. Antibiotic treatment of children with sorethroat. JAMA 2005; 294: 2315-2322

16. Schaad UB, Kellerhais P, Altwegg M; Swiss pharyngitis study group. Azithromycin versus penincillin $\mathrm{V}$ for treatment of acute group A streptococcal pharyngitis. Pediatr infect Dis J 2002; 21: 304-308

17. Casey JR, Pichichero ME. Metaanalysis of cephalosporins versus penincillin for treatment of Group A streptococcal tonsillopharygitis in adults. Clin Infect Dis 2004; 38: 15261534
18. Akanbi AA, Taiwo SS, Babtunde SK, Onile BA, Abdulraheem IS. Antibiotic susceptibility pattern of streptococcus pneumoniae in Ilorin, Nigeria. Afr J clin exptal microbiol 2004; 5: 172-176

19. Malik et al. Ampicillin and Amoxycillin. Pediatrics in Review 2006: $27: 434-436$

20. Bisno AL, Gerber MA, Gwaltney JM Jnr, Kaplan EL, Schwartz RH. Practice guildeline for the diagnosis and management of group A streptococcal pharyngitis. Clin Infect Dis J 2002; 35: 113-125

21. Tomasz A. Antibiotic resistance in streptococcal pneumoniae. Clin Infect Dis 1997; 24 (Suppl 1): 85-88

22. Klein JO. Current issues in upper respiratory tract infections in infants and children: rationale for antibiotic therapy. Pediatr Infect Dis J 1994; 13 (1 Suppl 1): S5-9

23. Taiwo SS, Onile BA. Penincillinresistant streptococcus pneumoniaeA review. Afri J Clin Exptal Microbiol 2004; 5: 78-107

24. Cohen R, Levy C, Doit C, De La rocque F, Boucherat M, Fitoussi F et al. Six day amoxicillin vs. ten-day penincillin V therapy for group A streptococcal tonsillopharyngitis. Pediatr infect dis J 1996; 15:678- 682 